\title{
Research of Chinese garment Enterprises Collaborative R\&D Platform Architecture
}

\author{
Li Li, Jingjie Luo, Ying Zhang \\ Fashion and Art Design Institute, Donghua University, Shanghai 200051, China
}

\begin{abstract}
Apparel products' R\&D was complicated system engineering and there were some problems in the $R \& D$ and production process, such as time constraints, poor coordination between departments, numerous miscellaneous details, and prominent contradictions in remote management and so on. So how to improve the ability of enterprises to cope with the changing of users' needs and develop new products became the key to the survival and development of enterprises. In this article, the analysis and research of applying CSCD (Computer Supported Cooperative Design) to modern garment enterprises were made and the architecture available to Chinese garment enterprises collaborative $R \& D$ platform was also analyzed.
\end{abstract}

Keywords-apparel products $R \& D$; collaborative design; collaboration platform architecture; information Processing; data base and data mining.

\section{INTRODUCTION}

With the advent of knowledge economy era, the original $\mathrm{R} \& \mathrm{D}$ and production management has been unable to satisfy the needs of modern garment enterprise. The original R\&D ideas have changed from division of labor, order, and based on material production to collaborative, parallel and based on information process, and the reasonable application of the information technology has become an important factor to improve the overall strength of the modern garment enterprise.

With the fierce global market competition, how to improve the ability of enterprise to cope with the changing of users' needs and develop new products become the key to the survival and development of enterprises. So in the modern garment enterprises, manufacturing industry and the field of product design, the modern design and advanced manufacturing technologies, such as virtual prototype technology, virtual reality, and collaborative design and so on, appeared ${ }^{[1]}$. CSCD-Based was more suitable to build collaboration platform for modern garment enterprises. The platform construction would help enterprises to improve the products' R\&D capability, shorten products' R\&D time, decrease the products' $R \& D$ cost and strengthen the cooperation between departments and enterprises. And it also could help the enterprises to organize all departments $R \& D$, manufacture resources and develop new products in a short time, and enhance the competitiveness of enterprises finally.

\section{TO ANALYZE THE STATUS AND DEMAND OF THE GARMENT ENTERPRISES COLLABORATION PLATFORM}

\section{A. Collaborative design definition}

Cooperative design is carried on by two or more subjects to complete a design objective, whom completed the design objective together with a different design task through the certain information exchange and coordination mechanism ${ }^{[2]}$. Collaborative design had the following characteristics:

i) Many corpuses: two or more experts participated in design activity usually.

ii) Distribution: the CSCD system with distribution of time and space, so the designers could join the system and participate in the design at different times in different locations.

iii) Heterogeneity: CSCD system was usually cross-industry, cross-enterprise and cross-department; therefore it had the heterogeneity of data, knowledge, hardware and software.

iv) Coordination: each expert should complete the common design goals together and maintained the validity and consistency of data by the concurrency control algorithm.

In addition, because the cooperative objective and collaborative method are different in CSCD applications field, there were other characteristics, such as collaborative design with the characteristic as higher requirements in the real-time, reliability ${ }^{[3-4]}$.

From the perspective of product life cycles and knowledge accumulation, and all aspects of apparel products that from market researching, product planning, conceptual design, style design and structural process to prototyping assessment, then to the production could be managed incorporated into the collaborative design.

\section{B. The status of domestic garment enterprise collaboration}

Currently, the majority of Chinese garment enterprises products design were sub-sector and top-down longitudinal serial R\&D mode as figure 1 . Now days, to seek further development and control operating costs, Chinese garment enterprises companies have been seeking collaborative ways to accomplish product development and production as figure 2. In the implementation of collaborative design process, we could experience some problems such as long R\&D cycle, inadequate enforcement, large difference between products and design and so on, which should be 
attributed to geographical differences, poor communication between the various functional or different regions departments and between cooperation mechanisms. So a real sense of coordination could not be achieved and the operational efficiency and market competitiveness of garment enterprises were restricted to some extent.

The leading domestic enterprises began to try to apply the collaborative platform and realized the knowledge of acquisition, sharing, innovation and application initially. But there were some issues should be resolved in the construction and use of domestic collaborative platform, such as the difference with the standard and basis of information, the lack of collaborative design environment, design and technology parallel collaboration missing, design knowledge transferring and sharing poorly, collaboration platform for the enterprise concerns and so on.

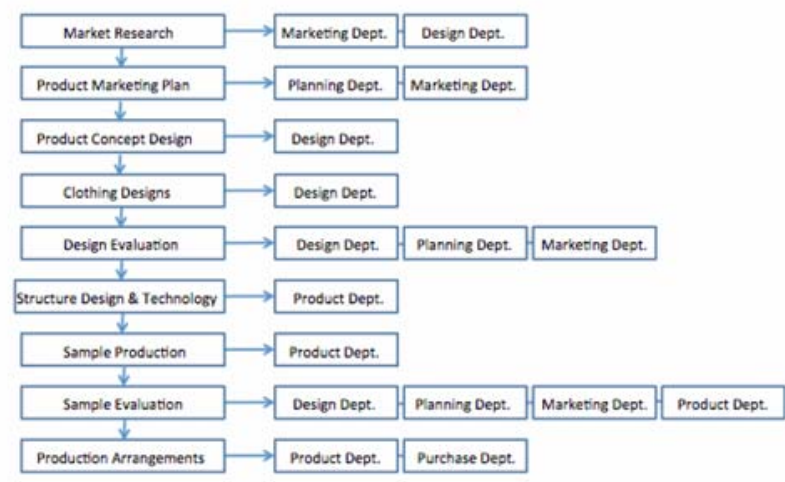

Figure 1. Garment Enterprises Longitudinal Serial Development Mode

\section{The status of garment enterprise products data management}

Enterprise information system included product lifecycle management (PLM), computer-aided design (CAD), supply chain management (SCM) and enterprise resource planning (ERP), and so on. PLM for apparel product $\mathrm{R} \& \mathrm{D}$ and product data management to the U.S. Parametric Technology Corporation PTC was particularly prominent, and shared a large market. The corporation which provided some solutions to Nike, Adidas, Li Ning and other famous garment enterprises, some of which were considered as the classic cases of the PLM applications in garment enterprise.

As the garment industry was a labor-intensive industry and the overall information technology started late, so the systematic administrative people who were familiar with the business model of garment enterprise and mastered the information technology were scarcity, which conflicted with strong demand for information technology in garment enterprises.

The PLM had been applied more and more widely in Chinese garment enterprises, but the product data management system used in collaboration platform was still in the initial trial process. We researched the collaboration platform architecture for Chinese garment enterprises in this study and we hoped from the information system construction area to solve design parallel collaboration missing, design knowledge transferring and sharing poorly and other problems in the construction and application of the collaborative design platform for Chinese garment enterprises.

\section{THE PLAN OF COLLABORATIVE PLATFORM FOR CHINESE GARMENT ENTERPRISES}

\section{A. The abstract of collaborative platform architecture}

As the regional dispersion of design resources and collaborative units, collaborative design products were completed collaboratively by different design units of multi-regions and then sent to different factories in different regions to produce and audit samples. So the cross-regional collaborative design was to focus on the issue. These different regions of the design resources should be able to be shared and use consistent of product data.

However, the restrictions based on the wide area network, aiming at the ways design resource management data in different regions, two main collaborative platform architectures as follows:

i) Architecture one: the physical and logical all unified coordination

ii) Architecture two: physical dispersed and logical unified regular data synchronization

\section{B. Federated collaboration of both physical and logical unification}

i) Plan description

First, it is needed to set up a PLM design center, with which the other areas can make collaborative design through WAN (Wide Area Network) by the means of replica, whose server is supposed to be equipped with and designed by each area. In this case, the design organizations and design centers of different areas can cooperate as one development group to unify the design flow, to synchronize and share the data, and to finish the garment design, thus integrating a virtual garment design center.

All the design data and design flow will be deposited and operated in the main server of PLM design center. And then forming a LAN (Local Area Network) in each region, which should be equipped with at least one supported replica server for replica cache of the design content. Next, connect with PLM center through WAN, and equip the replica center with firewall at both ends to ensure data transmission safety.

The main server and the supported server constitute a distributive data vault, which is to accelerate downloading local products data. Meanwhile, as the diagram below, the main server and the supported server can achieve regularly automatic data synchronism by synchronization mechanism of this system. As for the situation where instant update is required, handwork is available for interactive update. 


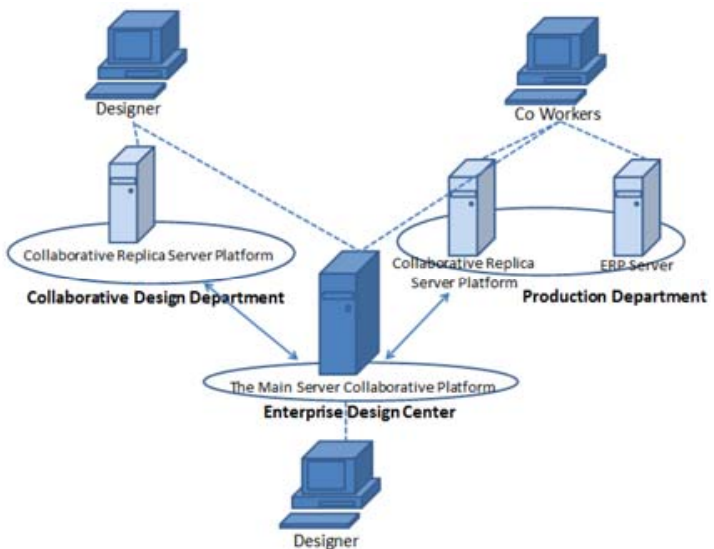

Figure 2. Allopatric Collaboration Platform Architecture 1

\section{ii) Plan Merits}

Since the collaborative departments of each region and design center co-work on one PLM platform, controlling flow and sharing data are the same with PLM in LAN.

- Sharing data and operating flow in real time so that there is no time lag.

- The architecture is mature and implementation risk is low, which centralize the maintenance management work.

iii) Plan Defects

Since all the data visits and business flow proceed in PLM center, the system configuration of which should be extremely high.

Much higher requirements are claimed to the stability of WAN in daily work.

C. Regular data synchronism of physical dispersion while logical unity

i) Plan description

Set up collaborative design platform based on design center, and establish regional branch design center. Each branch center can be independent from the home site. The designers of each region operate their local PLM, and manage the design through visiting local PLM system. Every day the branch center and home site regularly synchronize data through data package to achieve regional collaborative design, as Figure 3.

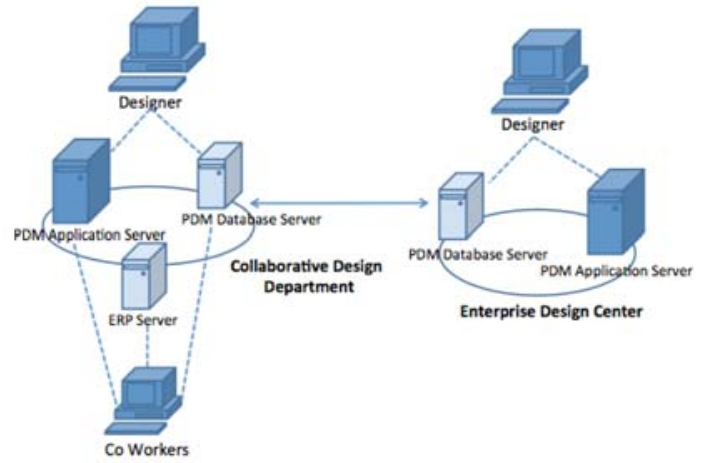

Figure 3. Allopatric Collaboration Platform Architecture 2 ii) Plan Merits

Each branch center can operate independently. In case there is any failure arising to the home site, the impact to the local design is rather low.

- Reading the product data in locality in daily application contributed to their good performance.

- The data packages synchronize when the system is not busy, which means it occupies only a little network.

iii) Plan Defects

The data read by home site and branch center in daily life is not up to date, and the longest time lag is one day. As a result, each PLM system is not synchronized in most of the time.

- Check and approve the flow cannot be done at the same time.

- Technology and maintenance cost a lot, and the maintenance is rather difficult.

- Each region requires a set of server system.

D. The comparison of the architecture plans of distributed collaborative platform

i) Data transmission quantity

Since the data is needed to be synchronized is transmitted through either data package or background task, the total data transmission quantities of the two plans are nearly the same.

ii) System hardware and network configuration

In the first plan, PLM server integrates all the business processes, which requires that it be of high system performance and stability.

While in the second plan, the servers of the home site and each region are mainly used to support local design data management, which means they load equal performance and requires not too much of the network in daily application.

From the point of hardware, the first plan can focus on investing in servers of high performance and high stability, and may support more complicated product data configuration management; while the second plan need equip servers in many branch centers, and may cost much more.

iii) Application maintenance

The first plan is able to concentrate system maintenance and management team on the center, which makes for forming much stronger and more stable team.

The first plan needs to build much stronger teams of system maintenance and management at many branch centers, and the varied staff quality may arouse risk to system application maintenance.

To sum up, the second plan is usually adopted in the different PLM of upstream and downstream firms to transmit data; while the firms that require real-time adopt the first plan and highly unified business, for its architecture is of concentrated distribution. 


\section{E. The choice of the architecture of distributed collaborative platform}

Generally, there are two kinds of the distributed collaborative design modes of China garment enterprises. The first one is the collaboration among the departments within an enterprise or the collaboration among the branch offices within a group. The second one is the inter-enterprise collaboration with the other cooperated organization.

Since the design flow of an enterprise or a group is unified, so is data standard, and the business of which requires instant and efficient, federated collaborative architecture is adopted either among design centers or between design center and other departments. On the premise of flow unification and standard unification, the architecture of federated distributed collaborative design platform constitutes a virtual technique center, in which all the product design data and flows operate on the main server, and the main server and the supported servers constitute a distributed data vault, which allows all the designs and related collaborations to implement on one PLM center.

Most of distributed collaborative designs of China garment enterprises choose inter-enterprise collaboration. Since the flows and standards of different enterprises may be different, and each enterprise has its own information system, inter-enterprise distributed collaborative platform may adopt physical dispersed while logical unified regular data synchronized architecture.

The architecture of regular data synchronized distributed collaborative platform implements regional design or cooperated enterprises operating local PLM, which in each region can be totally independent. Meanwhile, each region regularly synchronizes data through data package, which integrates the information system and collaborative platform of the regions. What is worth mentioning is that building the collaborative $\mathrm{R} \& \mathrm{D}$ chain does not mean to overturn the existing information system of an enterprise, but aim to satisfy the need of inter-enterprises by integrating the existing systems sufficiently.

\section{CONCLUSION}

First, with distributed collaborative platform, the designers is able to get to know the market and customers' need at the first time, and make the designers of varied regions cooperate to develop the most needed products; second, connecting with the system of purchase, production and after-sales service conduces to reduce cost and improve efficiency; third, forming the digitized product developing chain enables the enterprise to have access to the latest information around the global market, and finish the design efficiently so as to bring an enterprise the best business opportunity, and make the customer satisfied to their heart.

For most of China garment enterprises, it is better to realize the significance and importance of building such collaborative $R \& D$ chain, which contributes to improve their innovation ability and market response ability, and thus enables them to remain invincible in the intense market competition.

\section{V.ACKNOWLEDGEMENTS}

The research work was supported by "the Fundamental Research Funds for the Central Universities”. No.13D110732 and No.13D210704.

\section{REFERENCES}

[1] Rui Yannian, Liu Wenjie, Guo Xuhong. Cooperative design.China Machine Press,2003.

[2] Pan Yunhe. Intelligent CAD methods and models. Beijing: Science Press, 1997.

[3] Shi Meilin,Xiang Yong.The theory and application of computer supported cooperative work. Beijing: Electronic Industry Press,2000.

[4] Stork,U·Jasnoch.A collaborative engineering environment.Proceedings team CAD work shop on collaborative design.Atlanta.GA,1997.

[5] Narang, A.,Gupta, R,Joshi, A.,Garg, V.K.Highly scalable parallel collaborative filtering algorithm .High Performance Computing (HiPC), pp.1-10,2010.

[6] Li Jun, Cao Xiaojie, Liu Xiaogang, Collaborative Branded Apparel Design System Based on Knowledge Management, Journal of Donghua University(Natural Science),38(1),pp. 41-45,2012.

[7] Jiang Qijun. China textile and garment enterprise collaborative innovation motivation and formation process. Enterprise Economy,Vol.6, pp.37-39,2007.

[8] ZHAO Gang Architecture research of garments enterprise message management system, Electronic Design Engineering, 20(23), pp.12-18, 2012.

[9] Chen Hong, Collaborative product design and development in textile and garment industry, Spinning technology, Vol.9, pp.57,2005.

[10] Gao Changkuan, Hu shouzhong.Study of clothing industrial cluster internal interaction. Journal of Silk, pp.75-80,2014. 